\title{
İran Siyasal Kültü̈ründe Şia: Devrimden Günümüze İran Siyasetinde Şiiliğin Etkisi
}

\author{
Kübra Y1lmaz*
}

\section{Öz}

Bu çalışmanın amacı, Şii mezhep anlayışının İran'ın siyasal kültürü ve dolayısıyla İran'ın iç ve dış politika çizgisi üzerinde ne ölçüde belirleyici olduğunun tespit edilmesidir. Çalışma, İran Devrimi ile Şii mezhep anlayışının devletin yeniden yapılandırılması süreci ve dış politika yaklaşımının gelişimi üzerinde belirleyici olduğu kabulünden hareket etmektedir. Buradan hareketle çalışmanın temel argümanı, İran'ın devrimden sonra geçirmiş olduğu dönüşümün Şii anlayışı ekseninde geliştiği yönündedir. İran'da Safevi Devleti’nden itibaren kurumsallaşmaya başlayan Şii mezhep anlayışı, ülkenin sosyal, siyasi ve ekonomik gelişiminde başat rol oynamıştır. Şii mezhep anlayışı, Tütün Protestoları (1890) ve Meşrutiyet'in ilanı (1906) örneklerinde olduğu gibi sosyal ve siyasal olayların merkezinde yer almıştır. Tarihsel süreçte olduğu gibi Şiilik, devrimden sora da İran'ın siyasi yapısı üzerinde belirleyici değişkenlerden birisi olarak ortaya çıkmıştır. Devrimin ardından Pehlevi Hanedanlığı döneminde Fars sembolleri üzerinden gerçekleştirilen ulus kimliği inşasından vazgeçilerek, Şii ritüelleri ve sembolleri üzerinden devlet kimliği inşa edilmeye çalışılmıştır. Dolayısıyla, günümüzde İran'ın sosyal, kültürel, ekonomik ve politik yaşamının biçimlenmesinde Şii mezhep anlayışının son derece etkili olduğunu söylemek mümkündür.

Anahtar Kelimeler: İran, Şia Mezhebi, İran Devrimi, Siyasal Kültür, Velayet-i Fakih.

Bilim Uzmanı, Hasan Kalyoncu Üniversitesi, Siyaset Bilimi ve Uluslararası İlişkiler, kubr.yilmaaz@gmail.com, ORCID: 0000-0001-5696-3955 


\title{
Shia in Iranian Political Culture: The Impact of Shia on Iranian Politics from the Revolution to the Present
}

\author{
Kübra Y1lmaz*
}

\begin{abstract}
The aim of the study is to determine to what extent the understanding of the Shiite sect is determinant on Iran's political culture and therefore on Iran's domestic and foreign policy. The study is based on the assumption that the Iranian Revolution and the understanding of the Shiite sect are decisive on the restructuring of the state and the development of the foreign policy approach. From this point of view, the main argument of the study is that the transformation that Iran experienced after the revolution has developed on the axis of the Shiite understanding. The understanding of the Shiite sect, which started to be institutionalized in Iran since the Safavid State, played a leading role in the social, political and economic development of this country. The understanding of the Shiite sect has been at the center of social and political events such as the Tobacco Protests (1890) and the declaration of the Constitutional Monarchy (1906). As in the historical process, Shiism has emerged as one of the determining variables on Iran's political structure following the revolution. After the revolution, the national identity construction based on Persian symbols during the Pahlavi Dynasty was abandoned, and it was tried to be rebuilt on Shiite rituals and symbols. Therefore, it is possible to say that the understanding of the Shiite sect has been extremely influential in shaping the social, cultural, economic and political life of Iran today.
\end{abstract}

Keywords: Iran, Shia Sect, Iranian Revolution, Political Culture, Velayat-e Faqih.

M.A., Hasan Kalyoncu University, Political Science and International Relations, kubr. yilmaaz@gmail.com, ORCID: 0000-0001-5696-3955 


\section{Giriş}

Kafkaslardan başlayarak Ortadoğu, Güney ve Orta Asya'yı birbirine bağlayan İran, jeopolitik bakımdan son derece önemli bir coğrafyada konuşlanmış olup kara ve deniz yolları ile bu merkezleri birbirine bağlaması açısından stratejik bir konuma sahiptir. İran, geçmişten günümüze sahip olduğu stratejik konumunun yanında, kendisine özgü politik kültürü ve siyasal rejimi ile dikkat çekmektedir. Bu bağlamda İran, siyasi, dini, ekonomik ve tarihsel boyutların kombinasyonundan oluşan bir kültüre sahiptir (Farsoun \& Mashayekhi, 2005, s. 11-15).

Bu unsurların birleşimi, İran halkına özgü devrimci bir kültürün oluşmas1na imkân tanımıştır. Bu bağlamda günümüzde İran İslam Cumhuriyeti'nin politik kültürünün şekillenmesinde İran'da kurulmuş en eski medeniyet olan Perslerden başlayarak bu coğrafyada inşa edilmiş birçok medeniyetin biriktirdiği sosyo kültürel miras kadar, İslam dinini İranlıların kabul etmelerinden sonra, İslamiyet'i kendi siyasal ve kültürel özellikleriyle sentezlemeleri sonucu ortaya çıkan Şia mezhebinin etkisi son derece önemlidir (Lapıdus, 2003, s. 393-396). Bir anlamda Şiilik, İran'ın eski devlet, din ve siyaset geleneklerinin ve onun İslam ve dünya medeniyetlerine kültürel katkılarının bir yan ürünüdür. Bu nedenle İran, Şiiliğin anavatanı ve sıçrama tahtasıdır. Aynı zamanda Şiilik, tıpkı Zerdüştlüğün eski Sasanilerde olduğu gibi, İslami İran'ın vazgeçilmez bir parçasıdır (Farazmand, 1996, s. 227-229).

1979 y1lında gerçekleştirilen İran Devrimi’nden sonra, yeni rejimi ile bölgede bir tehdit unsuru olarak algılanmaya başlayan İran, çok çeşitli iç ve dış meselelerle, özellikle de Irak'a karşı sekiz yıllık savaşla, rejimin bir arada var olan diğer siyasi eğilimini, yani milliyetçiliğini güçlendirdi. Şii coşkusu ile İslam Cumhuriyeti evrensel İslami ideolojisini giderek ulusal bağlama uyarladı. Bu bağlamda, İran'ın politik kültürün anlaşılmasında, milliyetçilik, sosyal adalet duygusu ve monarşist geçmişin izleri yanında belki de en çok etkili olan Şiiliğin anlaşılması oldukça önemlidir. Çünkü İran Devrimi ve devrimden sonraki rejim inşa sürecinde son derece etkili olan Şiilik, günümüz İran'ın sosyal, siyasal, ekonomik ve kültürel yaşamının en önemli belirleyicilerinden biridir. Bu bağlamda bu makalede, İran'ın gerek iç politikada devlet yapılanmasında gerekse de dış politika yapım sürecinde özellikle Şii nüfusun yaşadığı bölgeler üzerinde Şii inancını ve kültürünü nasıl kaldıraç olarak kullandığına odaklanılacaktır. 


\section{2. Şiiliğin Ortaya Çıkışı ve Tarihsel Süreçte İran Politik Kültürüne Etkileri}

Bir siyasi teşekkül olarak Pers İmparatorluğu'nun tarih sahnesine çıkmasından sonra birçok medeniyete ve siyasi yapıya ev sahipliği yapmış olan İran, stratejik konumu itibariyle, tarihsel süreçte pek çok kez istilaya uğramış, bu çerçevede birçok medeniyet izlerini bu bölgede bırakmıştır. Uğramış olduğu istilalara, bu coğrafyada kurulan farklı kültürel hegemonyalara, iç isyanlara ve dini kimliğindeki değişikliklere rağmen İran, kültürel kimliğini oluşturan ana dinamikleri korumayı başarmıştır. Günümüzde İran'ın politik kültüründe etkili unsurların belki de en başında gelen, Şia inancının oluşmasının temelleri, İslamiyet'in doğuşundan sonra başlayan fetih hareketleri sonucu, İran'ın İslam kültür coğrafyasına dahil edilmesi ile atılmıştır (Muaddel, 1992, s. 154-155).

Emeviler döneminde yaşanan Kerbela olayı, İslam dünyasında, Şii inancın ortaya çıkışı ve şekillenmesinde tetikleyici bir faktör olmuştur. Hz. Ali ile Muaviye arasında başlayan hilafet çekişmesinde Hz. Ali ve Hz. Hüseyin'in yanında yer aldıklarından dolayı İranlılar, Emevi hanedanı döneminde baskıya maruz kalmışlardır. Bu süre zarfında Emevi hanedanı, bir Araplaştırma politikası izleyerek çoğunluğu Farsi olan Müslümanlar cizye vermeye zorlamıştır (Aytaç \& Durgun, 2012, s. 529).

Hz. Ali'nin ve sevenlerinin Kerbela'da çektiği acıların etkisi altında İranlıların ümmet içinde ötekileştirilmesi ve kolektif psikolojilerinin inşası bu dönemde gerçekleşmiştir. İranlıların bu baskıya karşı milli kimlikleri üzerinden oluşturdukları tepki, kültürel inançla yoğrulmuş Şiiliği ortaya çıkarmıştır. (Aytaç \& Durgun, 2012, s. 529). 874 yılında On ikinci İmam olarak kabul edilen Mehdi'nin kayboluşu ve büyük gaybet sürecinin başlaması, Şiilerin Mehdi'nin çıkacağı döneme kadar beklenilmesi gerektiği biçiminde algılandı. Kurtarıcı Mehdi'nin ortaya çıkacağı ana kadar eylemsiz kalınıp harekete geçilmemesi, mağduriyetin yarattığı bir itaat biçimine dönüşmüştür (Demirkılınç, 2017, s. 34-35).

Ötekileştirme politikaları altında ayrışmaya başlayan Şii Müslümanların kolektif kimliklerine kaybolduğuna inandıkları kurtarıcı imamın beklentisi eklenmiştir. (Aytaç ve Durgun, 2012, s. 529). Şii inancına göre kayıp imamın dönüşü, dünyanın sonunu ve yeryüzünde ideal ilahi yönetimin kurulduğunu işaret edecektir. İranlılar, Hz. Ali'den sonraki imamların sahip bu- 
lundukları siyasi gücü herhangi bir devletin otoritesi altında icra imkanları olmadığından dolayı Sünni hükümdarların emre altında takiye dönemini yaşamışlardır (Uyar, 2000, s. 77-78).

Tarihsel süreçte Şiilik, Safevi Hanedanlığı döneminde kurumsallaşmış, İran'ın politik kültürünün önemli bir unsuru haline gelmiştir. Kerbela'da yaşanan haksızlıklardan başlayarak geçmiş işgallerin hatıraları, olumsuz ve abartılı öteki korkusu nihayetinde Şiilik, Safevi hanedanı altında İran topraklarının on altıncı yüzyılda yeniden birleşmesi sırasında, ulusal özerkliğe dayanan modern bir milliyetçilik biçimine dönüştü (Farsoun \& Mashayekhi, 2005, s. 85). Bu dönemde On iki imam inancına dayalı Şiilik devletin resmi dini haline geldi. Bu nedenle İranlllar, esasen kendilerini Araplardan ayıran değil, aynı zamanda liderlik yapılarıyla daha yakından uyumlu görünen bir İslam biçimini benimsediler (Farsoun \& Mashayekhi, 2005, s. 85). Siyasal iktidarın gücünü Şii mezhebine dayandıran Safeviler, ulema sınıfını ise devletin kontrolünde bir bürokrasi aygıtı şeklinde teşkilatlandırmışlardı. Şah ile dini müesseseler arasında bağlantıyı sağlamakta olan Sadr, önceleri üç halifenin ritüelleşmiş olan lanetlenişinden sorumluydu. Süreç içerisinde Sadr'ın sorumlulukları kadıların ve muallimlerin atanmasından vakıfların yönetimine doğru kademeli bir şekilde doğru genişlemişti (Lapıdus, 2003, s. 395). Bu şekilde, İranlılar, yalnızca monarşiyi korumakla kalmayıp aynı zamanda sosyal adaleti, Sünni İslam'dan daha fazla vurgulayan bir İslam biçimi seçmişlerdir. Şeriati, Safevilerin devrimci bir dini takiyeyi çok sık kullanan bir inanca dönüştürdüğünü savunmuştur. Safevi hanedanından önce İslam, siyasette yalnızca sınırlı bir rolü olan dini bir kurumdu (Uyar, 2004, s. 203).

Ancak Safeviler, iki kurum arasında bir birlik yaratarak ulemanın işlevini değiştirdi. Bununla birlikte, ulemanın siyasi katılımı bireysel tercih açısından farklılık gösterdi. Bazı din adamları, rollerini yalnızca dini yasaları doğrudan etkileyen konularla sınırlı tutmayı seçerken, diğerleri siyasi sistemdeki işlevlerinin benimseyerek daha evrensel olması gerektiğini iddia ettiler (Kojoori-Saatchi, 2005, s. 37). Şii ulemanın siyasetteki gücü ve rolü zaman içinde dalgalanmaya devam etti. Kaçar Hanedanlığı döneminde rejimin mutlakiyetçi doğası nedeniyle gücü sınırlı olduğundan Şiilik, 19. Yüzyılın ortalarına, İran'ın kültürel ve sosyal yaşantısının en önemli bileşeniydi. Her zaman Kaçar yöneticileri tarafindan Şii gelenekleri, güçleri- 
nin meşrulaştırılması için kullanılmaya devam edilmiştir (Lapidus, 2003, s. 397-398).

Bu süreçte, İran'daki Şia nüfusun, yönetiminin çıkarak tamamı ile şiir ulemanın kontrolüne geçmesi ve içtihat anlayışının gelişmesi neticesinde bir taraftan merceiyyet ${ }^{1}$ müessesesi kurumsallaşırken diğer taraftan da ulema arasındaki hiyerarşik yapı sağlam temeller üzerine oturmuştur. $\mathrm{Bu}$ yapı içinde en üst noktayı ise Ayetullahlar işgal etmiştir (Arı, 2007, s. 82). Devletin birtakım yanlış uygulamalarının bir neticesi olarak halk, devletten uzaklaştıkça sosyal sorunların çözüm mercii olarak gördükleri ulemaya yakınlaşmışlardır. Bu durum ise, ulemanın halk üzerindeki otoritesinin artmasına yol açmıştır. (Uyar, 2000, s. 78-79).

Kaçar Hanedanlığının hakimiyet yılları İran'ın batı tarzı modernleşme hareketleri başlattığı bu bağlamda Batı ile olan ilişkilerin geliştiği ve İran'ın Batı'ya açıldığ yıllar olmuştur. Abbas Mirza döneminde başlatılan modernleşme faaliyetleri, Nasıreddin Şah döneminde de sürdürülmüş, bu süreçte Batı'ya eğitim amaçlı çok sayıda öğrenci gönderilmiştir. Bununla birlikte Batı ile geliştirdiği ticari ilişkiler, Batılı devletlerin yarı sömürgesi durumuna gelen İran ekonomini küresel piyasalar karşısında savunmasız bırakmıştır. Batılı devletlere Kaçar Hanedanı'nın vermiş olduğu kapitülasyonlar ile ekonomik hayatta ortaya çıkan olumsuzluklar, tütün isyanı olarak isimlendirilen tütün protestoları ile neticelenmiştir (Uyar, 2004, s. 203).

Sosyal ve ekonomik sebeplerle başlayan isyanın organizasyonunda liberal entelektüeller, tüccarlar kadar Şii ulema da etkili olmuştur. 1890'da Nas1reddin Şah'ın tütün satışını bir İngiliz tüccarın tekeline bırakması karşısına karş1 yükselen protesto gösterilerinin dini meşruiyeti, tütün içilmesine karş1 fetva veren ulemanın sözcüsü Ayetullah Hasan el-Şirazi tarafından sağlanmıştır. Şirazi, tütün kullanımının kayıp İmam Muhammed el-Mehdi'ye karş1 savaşla eşdeğer olduğunu ilan etmiştir (Lambton, 1987, s. 223).

Ulema, ulusal çıkarları yabancı egemenliğinden korumaya çalışan kilit dini otorite olarak, kendilerini ekonomik olarak destekleyen tüccar sınıfinın çok değerli bir müttefiki olduğunu kanıtlamıştır. Bu bağlamda bu olay, halkın örgütlenmesine önemli bir misyon yüklenen ve ileri dönemlerde

Şî̂ ulemanın uzun süreç içinde gerçekleştirmeye muvaffak olduğu, siyasî idareden bağımsız dinî hiyerarşinin en üst noktasını temsil eden müessese. 
siyasi değişimlerini yönlendirecek olan Şii din adamlarının artan gücünü göstermesi bakımından önem taşımaktadır (Lambton, 1987, s. 223). Tütün isyanının diğer bir önemli sonucu ise, İran'da meşrutiyet beklentilerini yeşertmek olmuştur. Protestolar sonucunda geri adım atmak zorunda kalan Şah'a gücünü sınırlandırılma noktasında İranlı entelektüeller, ulema ve Pazar esnafı tarafından baskılar artmıştır. Bu koalisyon, paylaşılan bir gelecek konusunda bir fikir birliği yerine, Kaçar hanedanı ve onun yabancı destekçileri olan ortak düşmanlara direnmek üzerinde inşa edilmiştir (Varol, 2016, s. 133).

$\mathrm{Bu}$ koalisyonda ulemanın rolü sıradan insanları seferber etmek ve ayaklanmaya meşruiyet sağlamaktı. Entelektüeller teorinin kaynağ 1 , çarş1 esnafı ise mali destekçiydi. Baskılar sonunda 5 Ağustos 1906' da Muzafereddin Şah, meşrutiyeti ilan ederek Milli İstişare Meclisi'ni açmak zorunda kalmıştır (Varol, 2016, s. 133).

Şii ulemanın, modernleşme uğruna yapılan birçok reforma direnmesine rağmen, mutlak monarşiden anayasal sisteme geçişi desteklemesinin en önemli sebebi eğitim ve yargı gibi önemli kurumları yeniden yapılandırarak ulemanın İran toplumundaki rolünü zayıflatan sosyal ve siyasi süreçleri engellemekti. Ulema için üç tür hükümet vardı. Bunlardan ilki, İmam'ın yönetimi, ikincisi mutlak bir monarşi, üçüncüsü ise, sınırlı ve anayasal bir hükümet biçimiydi. İmamın hükmü, onun görünmezliği nedeniyle imkansızdı. Anayasal bir hükümette şahın gücü sınırlandırılabilir ve böylece İslam toprakları kafirlere ve zalim bir yönetime karşı korunabilirdi. Bu muhakemenin bir sonucu olarak, ulemanın çoğunluğu için, kayıp imamın yokluğunda anayasacılık en iyi hükümetti ve ulemanın anayasaya katılmak dini bir sorumluluktu (Varol, 2016, s. 133).

Milli İstişare Meclisi'nde çok sayıda sandalye elde eden ulema, anayasanın yazılmasında da önemli rol oynadı. Bundan dolayı da anayasa en önemli ayrıcalıklar Şiiliğe tanınmıştır (Nader,1995, s. 1393). İran'ın resmi dini anayasaya göre Şii mezhebi olmuştur. Yargısal alanda ise, din ve devlet mahkemeleri olmak üzere ayrıma gidilmiştir. Şii ulema, dini mahkemeler üzerinde tam kontrol sağlamıştır. Bununla birlikte, Meclisin şeriata aykır1 yasalar çıkarmasını engelleyecek mekanizmalar oluşturulmuştur (Hüseyin,1988, s. 58-59). 1925 yılında bir askeri darbe ile İran'da yönetimi ele geçiren Rıza Şah Pehlevi döneminde merkezileşmiş modern bir devletin inşası yönünde atılan adımlar bu çerçevede uygulanan laik reformlar, 
İran'da Şii ulemanın aleyhine sonuçlanmış bu geleneksel yapıların İran politik yaşamından geri plana itilmesine yol açmıştır. Kum, Necef, Meşhed, İsfahan gibi kentlerdeki Şia'nın otorite kaynağı olan medreseler özek kalmayı başarmışlarsa da zorunlu hale getirilen seküler okullar vasıtasıyla dini eğitim veren kurumların alanı daraltılmıştır (Abrahamian,1982, s. 3236).

Ulema, eğitim alanı yanında yargı sistemleri üzerindeki kontrolünü de kaybetmiştir. Pehlevi hanedanı, İran ulusal kimliğinin inşasında Şii İslam'ın rolünü zayıflatmak için İslam öncesi İran değerlerini ve kimliğini de ön plana çıkarmaya çalışmıştır. Modernleşme ve merkezileşme politikaları Muhammed Riza Şah döneminde de devam etmiş, ulemanın çoğunluğu pek çok reformu hoş karşılamamış ve bu dönemde Şah rejimine taban düzeyinde güçlü ve etkili bir direniş üretmiş̧ir. Şii ulema bu süreçte bir kez daha siyasi nüfuz kazanmaya çalışmıştır (Keddie, 2006, s. 145).

Ulemanın artan gücüyle kısmen başa çıkabilmek için Şah, Beyaz devrim olarak isimlendirilen reformları başlatmıştır. İran toplumunun birçok kesimi başlangıçta reformları desteklese de reform sürecinin başarısız sonuçları, sonraki yıllarda İran toplumunun birçok kesimini Şah'a karşı birleştirmiştir. Özellikle toprak reformlarının ciddi sosyal, politik ve ekonomik sonuçları oldu. Şah'ın amac1, yönettikleri toprakları ele geçirerek sadece toprak ağalarının ve ulemanın gücünü zayıflatmak değil, aynı zamanda toprak ağalarının ve dini kurumların topraklarını dağıtarak kırsalda rejime sadık bir köylü sınıfı oluşturmaktı (Varol, 2016, s. 137).

Muhammed Rıza Şah dini kurumları İran'ın modernleşme sürecine bir engel olarak gördüğünden dolayı ulemanın gücünü sınırlandırmak istemiştir (Mackey \& Harrop,1996:220). Şii ulemanın kontrolündeki dini kurumlar ise kendilerine karşı yönelen bu politikalara yanıt vermek için zamanla politik olarak daha aktif hale gelmişlerdir. Özellikle Şah'ın Beyaz Devrim'inin önemli bir bileşeni olan toprak reformunda, İran'ın kırsal nüfusunun geniş bir kısmının faydalanmaması bununla birlikte bu reform ile birlikte büyük toprak sahiplerinin topraklarını kaybetmeleri İran'da memnuniyetsiz kesimlerin sayısını arttırmıştır (Abrahamian, 2008, s. 128). Yaşanan sosyal ve ekonomik sıkıntılara çözüm üretilememesi, pazar esnafının artan şikayetleri, bu kesimler ile yakın ilişkisi olan ulemayı, şahlık rejimine karşı oluşan tepkilerin merkezine itmiştir. Rejimin kendi alanını daraltması karşısında zaten tepkili olan Şii ulema, özel mülkiyeti yok ettiği bu nedenle 
de Şii geleneğine ve İslam hukukuna aykırı olduğu gerekçesiyle toprak reformunu şiddetle eleştirmiştir (Abrahamian, 2008, s. 128).

İran Devrimi'ne giden süreçte, sosyal ve ekonomik çöküntü karşısında çözüm üretemeyen şahlık rejiminin toplumsal tepkilere giderek sertleşerek cevap vermesi, rejimden rahatsız olan kesimleri, ulemanın etki alanına itmiştir. İran'daki alt sınıflara rejimin refah sağlayamaması neticesinde, bu kesimler üzerinde rejime karş1 en sert eleştirileri yönelten Humeyni ve diğer dini otoritelerin etkisi artmıştır (Takeyh, 2009, s. 90-93). İran'da Humeyni'nin dinleyici kitlelere Şia ilkeleri çerçevesinde sunduğu dini ideoloji, İslam'a göre 1300 yıllık sosyal standartların muhafazakâr bir biçimde yeniden yorumlanmasını içeriyordu. Humeyni, oluşturduğu bu ideolojik örgü içerisinde kendisini Allah'ın sözcüsü olduğunu iddia ederek ve liderliğini yalnızca İslam'ın ideal ilkelerini somutlaştırdığı inancına dayanarak kitleler üzerinde otorite kurmak istemiştir (Takeyh, 2009, s. 90-93).

Bu süreçte, Şeriati gibi İslamcı entelektüellerin üretmiş olduğu literatür de İslam'ın siyasal devrimci rolü ve sosyal sorumluluğu ön plana çıkartılarak şahlık rejimi sonrası kurulacak düzenin temelleri oluşturulmak istenmiştir (Moaddel, 1992, s. 154). Humeyni, 1971 y1lında kaleme aldığı "İslam Hükümeti" isimli eserde, İslami bir rejimin nasıl sistemleştirilebileceğini neden bir devrime ihtiyaç duyduğunu açıklamıştır. Şii inancı çerçevesinde önemli bir konu olan Mehdi'nin döneceğini ifade eden Humeyni, ancak Mehdi'nin dönüşüne kadar geçen süreçte İslam cemaatinin doğru yola ulaşabileceği İslami bir yönetime geçilmesinin zaruri olduğunu vurgulamıştır (Kojoori-Saatchi, 2005, s. 37). Bu bağlamda, Humeyni ve diğer Şii otoritenin İran'ın inanç dünyasında oldukça önemli olan Mehdi'nin gelmesi üzerinden inşa ettikleri söylem, geniş kesimler üzerinde etkili olmuştur. Süreç içerisinde Monarşi ile dini kurumlar arasındaki çatışma büyümüş ve sonunda 1979 'da esasen İran monarşisine son veren ve kontrolü Şii ulemaya devreden bir devrime yol açmıştır. (Kojoori-Saatchi, 2005, s. 37).

\section{3. İran Devrimi Sonrası Siyasal ve Toplumsal İnşa Sürecinde Şia İlkelerinin Etkisi}

İslam Cumhuriyeti'nin karizmatik liderliğini ve siyasetin kutsallaştırılmasını, yeni bir Şii İranlı benlik ve yeni bir İslam medeniyeti yaratma hedefini taşıyan İran devrimi, sadece modernite ve sekülerleşmeye değil aynı 
zamanda geleneksel olana karşı bir isyan olarak ortaya çıkan Şii İslam'ın dışavurumuydu. Bu paradigma, en bilgili din adamını yani Humeyni'yi, nihai dönüşünün yeryüzünde ilahi adaletin kurulmasıyla sonuçlanacağına inanılan On ikinci İmam'ın temsilcisi olarak kabul etti. Siyasi karar alma sürecine katılma yetkisine sahip yeni aktivist din adamları, Şii İslam tarihindeki ilk teokratik güce yardım etmek için ortaya çıarak siyasi gündemi belirleyen bir güç olarak ortaya çıktılar (Rahimi, 2009, s. 95).

Humeyni'nin yakın çevresi ve çekirdek destekçileri, Humeyni'nin karizmatik hakimiyetinin yükselmesinde de önemli roller oynadılar. Örneğin rejimde birkaç kilit pozisyonda bulunan Ayetullah Beheşti, Velâyet-i Fakih'i (Dini liderlik) anayasallaştırmak için en önemli çabayı ortaya koydu. Beheşhti'nin Hegelci tarih yaklaşımı, Humeyni'nin çocukluğundan lider olarak ortaya çıkışına kadar olan kişiliğini, Hz. Muhammed' in kişiliği ile devrimin sosyo-ekonomik süreci ise Hz. Muhammed'in peygamber olarak gönderildiği dönem ile özdeşleştirmiştir. Böylelikle Beheşti, hem Humeyni'ye hem de Devrime yüksek düzeyde İslami nosyon yükleyerek kutsamıştır (Assoudeh, 2019, s. 58).

1979 İran Devrimi’nin ardından, Şii inancın kontrolündeki eylemci din adamları ve militan ideologlar tarafindan yönetilen radikal hareket, İslamc1 bir siyasi düzen kurmak için devrimci bir yaklaşımla yeni düzeni inşa etmeye girişti (Arı, 2007, s. 533). Humeyni tarafından ileri sürülen ve anayasaya giren Velâyet-i Fakih siyasi ideolojisinin kurumsallaşması yeni bir Şii hükümeti anlayışını ön plana çıkardı (Algar, 1998, s. 30-365). Velâyet-i Fakih prensibi ve bu makama gelecek olan âdil ve dindar Fakih'e en geniş yetkileri sağlayan hükümleri, anayasal bağlamda Humeyni'nin liderlik rolünün zeminini oluşturmuştur. Bununla birlikte ahlaki ve mânevî prestije dayalı bir otorite elde eden Humeyni sağladığı bu güçle "toplumun lideri”" manasını taşıyan "imam" olarak kendisini kabul ettirmiştir (Algar, 1998, s. 30-365).

Velâyet-i Fakih terimi temel olarak Fâkih adlı dini liderin yönetimine atıfta bulunur. Aslında Velâyet-i Fakih kuramı Humeyni tarafindan 1960'larda ortaya atılmış ve Şia mezhebinin ideolojik temelleri üzerine oturtulmuştur. On ikinci imam olan İmam Mehdi'nin kaybolmasının neticesinde idari olarak bir boşluk meydana gelmiştir. Belirli bir süreçte vekiller tarafından ida- 
re edilmiş olan Şii toplumu Gaybet-i Suğra ${ }^{2}$ ile birlikte yöneticiden mahrum kalmıştır (Kurt,2018, s. 63). Allah'ın hükmünün 200 y1l ile sınırlı olmadığını ifade eden Humeyni, Şii fıkhındaki klasik yaklaşımının haricinde bir Velâyet-i Fakih teorisi ortaya koymuştur. Bu noktada kayıp imamın gelişine kadar başta dini konular olmak üzere birçok konuda kuralları kimin koyacağ 1 ve uygulayacağ1 gibi temel sorunlara çözüm mercii olarak İslam Devleti'nin kurulmasından sonra bu devletin başındaki yöneticiyi işaret eden Humeyni, Gaybet-i Suğra'dan sonra idare etme yetkisinin Fakihlere geçtiğini savunmuştur (Taflıŏlu, 2013, s. 96-97). Şiilikte “İmamet” kurumunun devamı olarak geliştirilmiş bir açılımı olan bu kuram ile Şia mezhebinde Ayetullahlar ve imamlara tanınmış olan insanüstü yetkiler ve makamlar, Humeyni tarafindan hazırlatılan yeni İran Anayasası'nın Velayet-i Fakih maddesi ile kurumsallaşmıştır (Kayabalı \& Cemender, 1990, s. 52). İslami anayasanın temel özelliklerinden önemli bir kısmı, Şiilik ruhuna uygundur ve ulemanın yirminci yüzyıldaki kaderindeki değişimleri yansıtır. Ulema bu kez kolektif güvensizlik duygularını ve çıkarlarını savunma kararlılığını yansıtan bir anayasa yazdı. Ulemanın yeni politik elitler olarak ayrıcalıklı statüsünü garanti altına almak için yerleşik mekanizmalar oluşturuldu. Ulemanın ayrıcalıklı rollerin devredilmesi ve sınırlı halk egemenliğinin kabulü, Şii hermenötik, mizaç ve tarih ile uyumluydu (Milani, 2005 , s. 105-106). Anayasa, rejimin dini vizyonunun siklıkla vurgulandığ şatafatlı, beş sayfalık bir girişle başlar. Devletin gerçekten İslami resmi bir ideolojiye sahip olduğunu iddia eder ve İran toplumunu, "militan ulema" ve Büyük Lider'in rehberliğinde "Müslüman bir millet" olarak tanımlar (Shambayati, 2004, s. 273).

İran Anayasasına göre Dini Lider, adaletli, dindar, cesur, sosyal ve siyasi konularda dahi, sağduyu, öngörü, yönetim ve liderlik özelliklerine sahip bir İslam alimi olmalıdır. Anayasa, ideal ve model bir toplum kurduğunu iddia ettiği ve daha önce de belirtildiği gibi, resmi bir ideoloji ilan ettiği için göze çarpan totaliter yönleri ağır basmaktadır. İran devletinin dünya çapında bir ümmet inşa etmeye çalışacağını ve kurtuluş mücadelelerinde "mahrum bırakılanlara ve "mazlumlara" yardım edeceği ifade edilmiştir. Önsözde, "kadınlar ve ideolojik ordu" için ayrı bir başlığın yanı sıra, "İsla-

On birinci İmam'ın şahadetinden sonra, hicrî 260 yılından 329 yılına kadar, yani 69 y1l Gaybet-i Suğra (Küçük Gizlilik) dönemidir. 
mi adalet", "Allah'ın hakimiyetini tüm dünyaya yaymak", "Allah yolunda cihadın ideolojik misyonu", gibi çeşitli ideolojik terimleri içerir (Kurun, 2017, s. 120-123).

İran politik sisteminin karmaşık yapısının merkezi noktasında bulunan Velâyet-i Fakih, İran politikasının en üstünde yer aldığından görev ve yetkileri anayasada ayrıntılı bir biçimde ele almış, Dini Liderlik makamının görev ve yetkileri anayasada 15 'in üzerinde maddesinde vurgulanmıştır. Velâyet-i Fakih inancının İran Devrimi'nin ayakta kalması ve devamı açısindan rejimin temeli olarak belirtildiği anayasada İran İslam Cumhuriyeti hâkimiyetinin Velâyet-i Fakih'e istinad etmemesi durumunda tüm ilahi meşruiyetini kaybedeceği ve Fakih'in İran Devrimi'nin devamlılı̆̆ındaki ana misyonu ve imametin devamlı rehberliği, 2. Madde ile vurgulanmıştır (Taflığlu, 2013, s. 105). Kayıp imam döneminde sadece İran halkının değil bütün İslam aleminin yöneticiliğinin Dini Lider'in yetkisinde olduğu, 5. Madde ile düzenlenmiştir. Velâyet-i Fakih bu durumda gaybet döneminde yasama ve egemenlik hakkına sahip tek kişi konumunda olmaktadır (Shambayati, 2004, s. 273).

Bununla birlikte anayasa ile dini lidere Şurây-1 Nigehban'ın (Koruma Konseyi) üyelerini değiştirme ve azletme, mahkûmların suçlarını af ya da affetmeme, savaş ve barışı ilan etme, cumhurbaşkanı adaylarını onaylama veya reddetme, Devrim Muhafizlarının ve silahlı kuvvetlerin komutanlarını görevden alma, tüm ülkedeki Cuma imamlarını tayini ve İslam Cumhuriyet'inin ana stratejisini tespit etme yetkileri tanınmıştır (Taflığlu, 2013, s. 105). Anayasa, gerçek hakimiyetin Allah'a ait olduğunu ve Allah'ın verdiği yasaları yorumlamakla yetkili olan tek otoritenin Fakih olduğunu işaret ettiğinden dolayı devlet mekanizmasın en üste bulunan Fâkih, bütün otoriteyi kendi kontrolünde tutmaktadır. Uzmanlar Meclisi tarafindan ömür boyu seçilecek olan Fakih, "İslami ilke" olan ya da olmayan her şeyin yorumundan mesuldü. Otoritesi ve yetkisi o kadar geniştir ki almış olduğu kararlardan dolayı herhangi bir meclise değil sadece Allah'a karşı sorumludur. Buna göre, Velâyet-î Fâkih İran'daki en güçlü kurumdur. Büyük ölçüde seçilen cumhurbaşkanının ve hükümetin gücünü Fâkih in gücü sinırlamaktadır (Safari,1989, s. 68-72).

Humeynî tarafından idealleştirilen Velâyet-î Fâkih kurumu ve devlet ile özdeşleştirmiş olduğu fakihin Allah'ın hücceti olduğuna yönelik fikirleri yönüyle devleti kutsayarak yüceltmesi ve onu ilahi olarak kimliklendirme- 
siyle, milleti merkeze alan söylemleri ile birbiriyle çelişiyor gibi görünse de aslında milliyetçilik prensibinin Batı'daki gelişimiyle de örtüşmektedir. Gaybet döneminde milleti merkeze, devleti paranteze alan İran'ın 'sivildin' yaklaşımı İran Devrimi'nden sonra resmi 'politik din' niteliğine bürünmüştür. Fars Şiiliğinin fetret döneminde İran'da, “din ü millet” birdir yaklaşımından, devrim ile Sünnî doktrinden daha belirgin bir şekilde "din ü devlet" birdir yaklaşımına geçilmiş olması, dinin-milletin bekası açısından devleti, vazgeçilmez olgu kılmıştır. Bundan dolayı din ve millet için devleti önceleyen bir politik yaklaşım gelişmiştir. Bu yaklaşım 'maslahat' kavramı ile, dinin nomistik değerlerini dönüştürmekten tutun dinin rükünlerini askıya almaya kadar varabilecek bir otoriteyi kontrolüne almıştır (Sar1, 2015, s. 103).

Humeyni, geleneksel fikıh ile modern bir dünyada bir ülkeyi yönetemeyeceğini bildiğinden dolayı çağdaş ideallerle uyumlu Şia ilkeleri üzerinden bir yönetim modeli inşa etmeyi hedeflemiştir. Onun iktidar teorisi, siyasi sistemin korunması ve uygunluğuna odaklanmıştır. Humeyni hükümeti bu nedenle geleneksel dini kullanan totaliter bir rejim olarak görülebilir (Assoudeh, 2019, s. 82-82). Dini ve zamansal işler için iki ayrı mahkeme oluşturan selefinden farklı olarak, İslami anayasa, ulema tarafindan kontrol edilen ve yalnızca İslami ilkelere dayanan birleşik bir yargı inşa etti. En yüksek yargı organı olan Yüksek Yargı Konseyi'ni kurdu ve diğer şeylerin yanı sıra, hükümleri ya İslam hukukuna ya da saygın Ayetullahların fetvalarına dayanması gereken yargıçları atama ve görevden alma yetkisi tanındı. Velâyet-î Fâkih, devletin Şiilikle kaynaşmasını meşrulaştırdıysa, yargı ile ilgili maddeler onu güçlendirdi (Milani, 2005, s. 97-99).

Devletin Şiilik ile kaynaşmasını tamamlamak ve şerî ve örfi kanunları arasındaki çatışmayı sona erdirmek için, anayasa, altı yıl görev yapan on iki üyesi Meclis yasalarının İslam ile uyumlu olmasını temin etmesi gereken Muhafizlar Konseyi'ni oluşturdu. Fakih, Meclis yasalarının İslam'a uygunluğunu tek başına inceleyebilecek olan konseyi oluşturan fukahadan altı tanesini atama yetkisine sahiptir. Hukukçu olması gereken diğer altı üye, Yüksek Yarg1 Konseyi tarafından hazırlanan listeden Meclis tarafından seçilmektedir. Hukukçular ve fukaha birlikte tüm mevzuatın anayasaya uygunluğunu inceleyecektir (Milani, 2005, s. 97-99).

Humeyni'nin devrimi, siyasi ve kültürel olarak Şiiliği korumak ve geliştirmekle ayrılmaz bir şekilde bağlantılıydı ve Şii otorite ve hukuk teorisi- 
nin dönüşümü 1979'un iki önemli sonucuydu. Devrimin başarısıyla, dini elitler, hem Velâyet-i Fakih'i hem de devrimi hemen kutsadılar. Devrimden sonraki süreçte örgütlü din, cami ve din adamlarının rolleri toplumda büyük ölçüde yükseldi. Bu nedenle, İslam Cumhuriyeti, geleneksel din ile rekabet eden bir siyasi dine dönüşmüştür (Kramer, 1987, s. 23-27). Ayetullah Ali Hamaney'e göre İran'daki İran Devrimi'nin beş amacı vardı. Bunlar; devrim, İslami sistemin oluşumu, İslam devletinin kurulması, İslam ulusunun oluşumu ve yeni bir İslam medeniyetinin oluşturulmasıdır. Yeni İslam medeniyeti ile İslam medeniyeti arasındaki temel fark, ilkinin İslam Cumhuriyeti'nin Şia inancının temel dinamiklerinden olan devrimci fedakârlık ve direniş kültürüne dayanan İran-İslam yaşam tarzına vurgu yapmasidır (Assoudeh, 2019, s. 91-92).

Rejimin, İran-İslam yaşam tarzına yönelik örgütlü propagandasının ardındaki nihai hedefi, yayılmacı amaçları için milliyetçi bir Şii anlatısı yaratmaktı. Genel olarak ele alındığında anayasa ile yönetim sisteminin İslamlaştırılması hızlandırıldıktan sonra iktidar elitleri 1980 yılından itibaren başlattıkları kültür devrimi ile İran toplumunun İslamlaştırılması hususunda girişimde bulunmuşlardır. Moghadam'ın (1994, s. 196) da belirtiği gibi, devrimin hegemonya mücadelesi, yalnızca ekonomi ya da siyaset politikası üzerinden kontrolü sağlama vasıtasıyla tamamlanamayacak kültür, kimlik ve özgünlügün İslami bir şekilde yeniden inşa edilmesi gayretiyle, farklı boyutlara taşınacaktır.

İran Devrimi'ni izleyen ilk dokuz yıl boyunca İslam Cumhuriyeti, temel amacı Tanrı'nın yeryüzündeki iradesini yerine getirmek amacıyla yönetilen militan bir devlete dönüşmüştür. Pragmatistlerle ve ideologlarla devlet yönetimi konusunda mücadeleler rejim içinde sürtüşmelere neden olmaya devam ederken, İran-Irak Savaşı (1980-88) devrimcilere radikal gündemlerini sağlamlaştırmaları için yeni bir firsat sağlamıştır. Savaş sırasında rejim, İran'ın gençleri arasında, öncelikle Şii kültürel geleneğine özgü sembollere ve yas uygulamalarına dayanan bir şehitlik kültürünü desteklemiştir. Böylesi bir kültür, Kerbela Savaşı'nda (680) kahramanca öldürülen Peygamber'in torunu Hüseyin' in şehit olmasının bir aktivist tarafından yeniden anlatılması üzerine şekillenmiştir (Kramer, 1987, s. 23-27).

İran'daki siyasi kültür, Şiilik tarihinden ve onun devlet dini olarak kurulmasından açıkça etkilenmiştir. İranlı Şiiler, Hz. Ali'nin yaşadığg adaletsizliği kendilerine hatırlatmaya ve bu tür adaletsizlikleri tarih boyunca onları 
bastıran liderlerle ilişkilendirmeye devam etmektedir. Şiiliğin siyasi boyutları, reddedilmesi imkânsız bir şekilde İran kültürüne yerleşmiştir. Şiilik, İranlılara, insanlar olarak adaletsiz bir dünya olarak algıladıkları yerde sosyal adaleti takip etmeye devam etmeleri gerektiğini hatırlatmaktadır (Kojoori-Saatchi, 2005, s. 38). Humeyni'nin siyasi Şiiliği, dini ritüelleri İran vatandaşlarının günlük yaşam aktivitelerine dönüştürülmüştür. Rejimin Şeriati'den ilham alan retoriği, her ülkeyi Kerbela, her ayı Muharram ve her günü Aşure olarak tanımlamıştır (Zubaida, 2011, s. 547-553).

Ayetullah Humeyni ve onun ruhban takipçileri, devrimden önce, din adamlarını ve İran toplumunun diğer birçok kesimini monarşiye karşı seferber etmeyi başaran, ardından İran İslam Cumhuriyeti'ni kuran, dini kurum içinde yalnızca bir hizipti. Devrim öncesinde ve sırasında monarşiye karşı muhalefet biçimleri hakkında var olan anlaşmazlıklar devrimden sonra da devam etti. Humeyni ve takipçileri Velayat-e Fakih fikrini savunurken, Kum'daki Ayetullah Şeriatmaderi veya Şiraz'daki Ayetullah Mahallati gibi ya Anayasa devrimi fikirlerine inanan ya da din adamlarının siyasetin d1şında kalmasını savunan başka önde gelen din adamları da bulunmaktaydı (Kadivar, 2017, s. 6-7).

Siyasallaşma konusunda Şii ulema arasındaki anlaşmazlıklar İslam Cumhuriyeti'nin, monarşi döneminde bile eşi görülmemiş bir ölçüde, ruhban düzeninin en yüksek kademesine baskı yapmasına neden oldu. İslam Cumhuriyeti, ruhban muhalefetiyle ilgilenmek için normal yargı sisteminin dışında Özel Ruhban Mahkemesi kurdu. Şeriatmadari, Qomi ve Ruhani gibi muhalif büyük Ayetullahlar ev hapsine alındı ve tıbbi bakımdan mahrum bırakıldı. Ayetullah Golpayegani ve Maraşi gibi Kum'da kalan yüksek rütbeli din adamları, Şiî Fıkhı kurallarını uygulayacak, Şii ritüellerini anacak ve ülkede Şiiliği teşvik edecek bir Şii hükümeti fikrini desteklediler. Bununla birlikte, devrimci rejim politikaları uygulanmaya başladıkça, rejimin politikaları zaman zaman Ortodoks Şeriat yorumlarından farklılaşmıştır (Kadivar, 2017, s. 6-7).

\section{Dış Politikada Şii İlkeler}

Şii inancı ekseninde şekillenmiş olan İran Devrimi'nin ilkeleri, İran'ın dış politikasının önemli belirleyicisi olmuştur. İran'ın dış politikasını incelerken, Büyük rehber Ayetullah'ın nihai rolü ve İran'ın dış politikasının 
karar verme sürecindeki etkisi oldukça önemlidir. Yönetim sisteminin en tepesindeki konumu silahlı kuvvetlerinin başkomutanı olma vasfiyla Dini Lider, ulusal güvenlik ve dış politika konularında nihai otoritedir (Kadivar, 2017, s. 6-7).

İran, hedeflerine ulaşmak için İran Devrimi'nden bu yana farklı dış politikalar izlemiştir. Devrim, İran toplumuna kamusal ve siyasi yaşamın her alanında göze çarpan egemen ideolojiyi sağladı. Bu nedenle İran dış politikasını sistemi besleyen Şii ideolojisi dışında sadece ekonomik ve siyasi çıkarlar açısından incelemek mümkün değildir (Osiewicz, 2019, s. 110). İran dış politikasında devrimin vermiş olduğu özgüvenle 1981'den 1989'a kadar ideolojik yaklaşım egemen olmuştur. İdeolojik yaklaşım, dış politikanın İslami ilke ve varsayımlara dayanması gerektiğine inanmaktadır. Başka bir deyişle, İran'ın idealist kesimleri, tüm karar vericilerin ve politikacıların ideolojik değerler temelinde davranması gerektiğine inanıyorlard1 (Soltani \& Amiri, 2010, s. 199).

Bu nedenle İran İslam Cumhuriyeti, uluslararası ortamı görmezden gelmeye ve hâkim uluslararası sistemin düzenlerini İran'ın İslami normlarıyla değiştirmeye çalıştı. İdealist yaklaşımın destekçileri, İran Devrimi ilkelerini bölgedeki diğer komşulara genişletebileceklerini ve İran Devrimi ilkelerinin genişlemesinin diğer ülkelerde de aynı devrimlere neden olacağını umuyorlard1. Diğer bir deyişle, ideolojik yaklaşımın destekçileri bölgedeki diğer ülkelere yönelik müdahaleci yaklaşım izlediler. Müdahaleci yaklaşım İran ile başta Basra Körfezi ülkeleri olmak üzere diğer ülkeler arasında düşmanlığa neden oldu. İran İslami hükümetinin hedefleri, İslam dünyasının çıkarları ile İran'ın çıkarları arasında dalgalandı (Soltani \&Amiri, 2010, s. 199).

İdeolojik dış politika yaklaşımın arka planı ise Şii ilkeler ile biçimlendirilmiştir. Bu bağlamda 1979 İran Devrimi'nin ortaya çıkışı, Şii faktörünün İran'ın dış politika düzenlemesindeki yerini güçlendirmek için bir dönüm noktasıydı. İran Devrimi aslında Şiileri gerçek kimliklerini ifade etmeye ve varlıklarını göstermeye cesaretlendirmişti. Bununla birlikte, devrimden sonra, bölgedeki Arap rejimlerinin ve özellikle Irak'taki Baas rejiminin benimsediği baskıcı politikalar, İran'ın dış politikasında Şii faktöründen yararlanmanın önündeki en büyük engeldi. İran Devrimi ideolojik farkl1lıkları yoğunlaştırmaya hizmet ettiğinden, İran, kendi Şii İslam söylemlerini kullanarak ya bölgelerin muhafazakâr Sünni İslam'1 ile ya da Saddam'ın 
Irak'ındaki Arap laik milliyetçileri ile çatışmaya girmiştir (Barzegar, 2018, s. 2-4).

İslam Cumhuriyeti, ideolojik ve devrimci felsefesi nedeniyle, özellikle devrim günlerinde, kendisini bu dönemde algıladığı yollarla bölgenin siyasi statükosunu değiştirmeye çalıştı. İran'ın yeni çabasının itici gücü, esasen İran Devrimi'ni daha fazla Şii devrimi olarak gören Sünni yönetici elitler tarafından uzun süre kendi ülkelerinin siyasetinin dışında tutulan Şii hiziplerdi. Daha sonra Suudi Arabistan, Bahreyn, Kuveyt ve Irak’taki Şii grupların İran ile yakın bir dostluk kurma girişimleri bastırıldı. En kötü baskı Irak'ta ve Saddam ve Baas rejimi tarafından gerçekleşti. Kültüreltoplumsal bağlılığın uzun geçmişleri göz önüne alındığında, İslam Cumhuriyeti Iraklı Şii gruplarla yakın ilişkiler kurmaya çalıştı. Bununla birlikte, girişimleri, Baas rejiminin Şii grupların faaliyetlerine daha fazla kısıtlama getirmesiyle sonuçlandı (Zarif, 2014, s. 3-8).

İran-Irak savaş1, Baas rejimi tarafindan İran ve Arap milliyetçi kimlikleri doğrultusunda iki devlet arasında bir mücadele olarak propaganda edilen savaş nedeniyle İran ve Irak Şiileri arasındaki dostluk duygusunu değiştirdi. İran'ın Şii faktörünü yönetme çabaları 1980'ler ve 1990'lar boyunca iniş çıkışlar yaşadı. İran'ın dış politikasında Şii faktörünü kullanarak Tahran'ın bölgede idealist-ideolojik bir dış politika geliştirdiğine inanılsa da devrimden sonraki birkaç ay dişında, pragmatik hedeflerin her zaman İran'ın dış politikasından kaynaklandığını iddia etmek gerekir (Abdo, 2013, s. 4). Bu süreçte Kudüs kuvveti ve İslam Cumhuriyeti'nin Ortadoğu'daki Kültür merkezleri, rejimin hem coğrafi hem de ideolojik olarak yeni bir İslam Medeniyeti arayışını yerine getirmede kilit temsilcileri olarak hizmet etti. Tahran, komşu ülkelerdeki askeri varlığını 'mesih misyonu' olarak kutsallaştırmışlardır (Zarif, 2014, s. 3-8).

1989'da Humeyni'nin ölümü, Ayetullah Hamaney ve Haşimi Rafsancani’nin ikili liderliğinin ortaya çıkması, Soğuk Savaş'ın sona ermesi ve 1991 Körfez Savaşı gibi iç ve dış gelişmeler, İran'ın dış politikası için yeni firsatlar ve zorluklar yarattı. Bu çerçevede İran, uluslararası sistemin karşı1ıklı bağımlı yapısı dışında etkin bir şekilde işleyemeyeceğini kabul etti. Ancak İran'ın komşu ülkelerle ikili ilişkileri istikrara kavuşturma girişimleri, diğerinin kimlik ve ideoloji odaklı dış politikasına ilişkin artan karşılıklı endişelerden dolayı uzun sürmedi (Uzun ve Ekşi, 2017, s. 208). Saddam rejiminin 2003 Irak Savaş1 sonucunda çökmesi, İran'1 Şii 
diriliş kavramı olarak adlandırılan bölgesel gücünü genişletmek, "Şii ç1karlarını ulusal kimlikler ile ilişkilendirme" üzerine kurguladığı bir hedef peşinde koşmaya teşvik eden bir diğer önemli olaydı. İran, bölgedeki tek Şii ülkesi olduğu için, Şiilerin yeniden canlanması İran'ın etkisinin hem bir ürünü hem de katkısı olarak algılandı. Dolayısıyla İran'ın gücünün artmasını bölgesel güvenlik ve istikrar için bir tehdit olarak algılayan Sünni Arap ülkeleri, Türkiye, İsrail ve ABD'nin endişesi haline geldi (Uzun \& Ekşi, 2017, s. 208).

Bu bağlamda, 2003 Irak krizinin ardından Irak'ta Şii ağırlıklı bir hükümetin kurulması, İran'ın dış politikasında Şii faktörünün yerini güçlendirmede bir dönüm noktası olmuştur. Yeni şartlar altında "unutulmuş Müslümanlar" olan Şiiler, birdenbire belirleyici güç olarak bölgesel güç denklemlerine girdiler. Yeni değişiklik tüm Ortadoğu'daki siyasi gelişmeleri etkiledi. Yeni gelişme, İran'ın Şii gruplarla ilişkilerini hem kitleler hem de devletler düzeyinde ilk kez geliştirdi. Şii gruplar, Sünni azınlığın egemenliğine dayanan geleneksel iktidar yapısını değiştirerek İran gibi bölgedeki dost devletler ve uluslarla yakın ilişkiler kurarak geleneksel ötekileştirmelerinden çekilmeyi çok önemli buldular (Barzegar, 2018, s. 2-4).

İran'ın bölgedeki Şii gruplarla yakın ilişkileri, güvenliğin yanı sıra ekonomik-kültürel firsatlar yaratmak için stratejik bir bağlantı kurmayı hedeflemiştir. Irak'ta, bu stratejik bağı kurmanın bir yönü, İran'a karşı herhangi bir geçmişi veya düşmanlığı olmayan yeni nesil dost elitlerin devletler düzeyinde kurulmasıdır. Bir diğeri, İran-Irak koalisyonunun, tüm kıyı devletlerinin dahil olduğu Basra Körfezi'nde yeni siyasi güvenlik düzenlemelerini şekillendirmek için iş birliği yapmak üzere oluşturulmasıdır (Barzegar, 2018, s. 2-4).

Stratejik bağlantıya dayalı olarak, Şii faktörü, İran'ın dış politikasında ulusal, bölgesel ve uluslararası düzeylerde firsat yaratmanın temeli oldu. Ulusal düzeyde, Şiilerin yönetici güç olarak varlığı, ikili ekonomik, siyasi ve güvenlik iş birliğini desteklemek için uygun bir zemindi. Irak Şiileri aracılığıyla kurulan stratejik bağlantının mantığı, Orta Doğu'daki gelecekteki güç oyunlarının daha çok devletlerin ekonomik ve güvenlik rollerini güvence altına almaya dayalı olacağı gerçeğine dayanmaktadır. Dolayısıyla İran'ın bölgedeki rolü, bölgedeki Şii siyasi müttefikleriyle stratejik ilişkilerinin derecesine, bu grupların devletlerin siyasi yapısı içindeki rolünü desteklemesine ve siyasi kamplar inşa etmesine bağlı kaldı. Şüphesiz uzun 
vadede Şii grupları faaliyetlerini ancak devletler çerçevesinde ve halkın desteği ile sürdürebilmektedir (Abdo, 2013, s. 5-6).

Orta Doğu, Ürdün Kralı Abdullah'ın Arap meslektaşlarını 2004 yılında Beyrut'tan Basra Körfezi'ne ideolojik bir Şii hilalinin ortaya çıkması ve İran'ın siyasi, dini ve askeri etkisini yurt dışına yansıtacak şekilde tasarlaması konusunda ilk kez uyardığından bu yana birçok kritik dönemeç yaşadı. Bugün bölgede yaşananlar, bölgenin Şii grupların kaderlerini kontrol altına aldıkları yeni bir düzene geçme mücadelesinin bir sonucudur. Diğer bir deyişle, Irak'ta Şiilerin yeniden canlanması, Ortadoğu'daki güç ve siyasetin temellerini Şii grupların lehine değiştirdi. Irak ve Bahreyn'deki Şiiler siyasi-sosyal hareketler ve reformlar için itici bir güç olsalar da Şii grupların kendilerini siyasi olarak öne sürme gücü ancak son zamanlarda elde edildi. Arap dünyasının ortaya attığı tüm bu yeni endişelere rağmen, İran'ın dış politikasındaki Şii faktörü, bölgedeki devletlerle dostane ilişkiler kurmada çoğunlukla İran'ın pragmatik politikalarına uygun hareket ediyor. Temelde güvenlik kaygılarıyla mücadele etmenin yanı sıra ekonomik-kültürel firsatlar yaratmayı hedefliyor (Barzegar, 2018, s. 2-4).

\section{Sonuç}

1979 Devrimi, İran'ın siyasete karşı tutumunda köklü bir değişikliğe yol açtı. Devrim sırasında geleneksel Şii İslami ideallerin siyasi değerlerle kaynaşması, popülist bir siyasi kültürün ortaya çıkmasına neden oldu. $\mathrm{Bu}$ siyasal kültürün temel özelliği, hükümetin sosyal adaleti sağlamakla yükümlü olduğu ve her yurttaşın siyasete katılması gerektiği yönündeki yaygın duygulardır. Devrim sonrası, İran Siyasi kültürü üzerinde Şiiliğin baskın bir karakter kazanmasında, büyük ölçüde Humeyni'nin devrim öncesi Şia'dan beslenen devlet tasavvuru belirleyici olmuştur. Şia mezhebinde Ayetullahlar ve imamlara tanınmış olan insanüstü yetkiler ve makamlar, Humeyni tarafından hazırlatılan yeni İran Anayasası'nın Velayet-i Fakih maddesi ile kurumsallaşmıştır. İran politik sisteminin karmaşık yapısının merkezi noktasında bulunan Velâyet-i Fakih, İran politikasının en üstünde yer aldığından görev ve yetkileri anayasada ayrıntılı bir biçimde ele almış, Dini Liderlik makamının görev ve yetkileri anayasada 15 'in üzerinde maddesinde vurgulanmıştır. Velâyet-i Fakih inancı, İran Devrimi'nin ayakta kalması ve devamı açısından rejimin temeli olarak belirtildiği anayasada sağlam bir temele oturtulmuştur. 
Sadece monarşiyi yıkmaya değil, aynı zamanda değerlerini İslam'dan alan yeni bir toplumla değiştirmeye de kararlı olan Humeyni, böylesine ideal bir İslami hükümetin uzun vadeli başarısının, kitlelerin bağlılığına ve katılımına bağlı olduğuna inanmıştır. Bu bağlamda din ve siyasetin kaynaştığ yeni bir toplum yaratmak için çalışırken, din adamlarını İslam hukukundaki uzmanlıklarına dayalı olarak dini rehberlik sağlamaktan sorumlu olarak gördü. Şah rejiminin ötekileştirdiği geniş halk kesimlerinin söylemleri ile yönlendiren Humeyni'nin devrim ve devrimden sonraki şöhretinin yanı sıra güçlü kişiliği, binlerce sadık takipçinin ülkenin siyasi kurumlarının laiklikten arındırılması için seferber edilmesinde önemli faktörler olmuştur.

Şii inancı ekseninde şekillenmiş olan İran Devrimi'nin ilkeleri, İran'ın dış politikasının önemli belirleyicisi olmuştur. İran'ın dış politikasını incelerken, Büyük rehber Ayetullah'ın nihai rolü ve İran'ın dış politikasının karar verme sürecindeki etkisi oldukça önemlidir. Bu bağlamda İran Devrimi'nin ardından İran rejimi ideolojisini yurt dışına ihraç etmeye çalışırken bölgede özellikle Şii nüfusun yoğun bir şekilde bulunduğu ülkelerde Şii ilkelerini Şii nüfus üzerinde kaldıraç olarak kullanmışlardır. İran'ın bölgedeki Şii gruplarla yakın ilişkileri, güvenliğin yanı sıra ekonomik-kültürel fırsatlar yaratmak için stratejik bir bağlantı kurmayı hedeflemiştir. Başta Irak olmak üzere bölge ülkelerinde bu stratejik bağı kurmanın bir yönü, İran'a karşı herhangi bir geçmişi veya düşmanlığı olmayan yeni nesil dost elitlerin devletler düzeyinde oluşturulmasıdır.

\section{Beyan}

$\mathrm{Bu}$ makale etik kurul kararından muaftır. Çalışmada katılımcı bulunmamaktadır. Çalışma için herhangi bir kurum veya projeden mali destek alınmamıştır. Çalışmada kişiler ve kurumlar arası çıkar çatışması bulunmamaktadır. Telif hakkına sebep olacak bir materyal kullanılmamıştır.

\section{Disclosure}

The article is exempt from the Ethics Committe Decision. There are no participants. The author received no financial support from any institution and there's no conflict of interest. No material subject to copyright is included. 


\section{Kaynakça}

Abdo, G. (2013, 10 April). The new sectarianism: The Arab Uprisings and the rebirth of the Shia'a Sunni divide, Broking Institute Report 29, https://www.brookings. edu/research/the-new-sectarianism-the-arabuprisings-and-the-rebirth-of-the-shia-sunni-divide/

Abrahamian, E. (1982). Iran between two revolutions. Princeton University Press.

Abrahamian, E. (2008). Modern İran tarihi. (D. Şendil, Çev.) Türkiye İş Bankası Kültür Yayınları.

Algar, H. (1998). Humeyni. Diyanet Íslam Ansiklopedisi, 18, 358-364, https://islamansiklopedisi.org.tr/humeyni

Arı, T. (2007). Geçmişten günümüze Ortadoğu: siyaset, savaş ve diplomasi. Alfa Yayinları.

Aykaç, B., \& Durgun, Ş. (2012). Çağdaşs siyasal sistemler. Binyıl Yayınevi.

Barzegar, K. (2018). The Shia factor in Iran's foreign policy. Belfer Center for Science and International Affairs, http://www.isrjournals. com/en/ iran-foreign-policy/813-the-shia-factor-in-irans-foreign-policy.html

Demirkılınç, S. (2017). Psikopolitik boyutuyla İran Devrimi. e-Şarkiyat İlmi Araştırmalar Dergisi, 9(1), 22-43, https://77f7a456-9ef8-47cc9061-43a46f90e667.filesusr.com/ugd/e0d7bd_0f7ce2d01bb94f9bb19 829041d6f08a2.pdf

Farazmand, A. (1996). Religion and politics in contemporary Iran: Shia radicalism, revolution, and national character. International Journal on Group Rights, 3(3), 227-257, https://www.jstor.org/stable/24674471

Farsoun, K., \& Mashayekhi, M. (1992). Iran: Political culture in the Islamic Republic. Routledge.

Hüseyin, A. (1988). İran'da devrim ve karşı devrim. (T. Cevdet, Çev.) P1nar Yayınlar1.

K. Farsoun, S. (2005). Introduction: Iran's political culture Iran political culture in the Islamic Republic. İçinde, S. K.Farsoun, \& M. Mashayekhi Iran political culture in the Islamic Republic (s. 1-20). Routledge. 
Kadivar, M. A. (2017). The Ayatollahs and the Republic: The religious establishment in Iran and its interaction with the Islamic Republic. $P O$ MEPS Studies, 28, 6-9, https://bit.ly/2Rfej6q

Kayabal1, İ., \& Arslanoğlu, C. (1990). Doğu problemi bir materyel ve kaynak araştırması (M.Ö. 1300 - M.S. 1989). Kendi Yayınları.

Kojoori-Saatchi, A. E. (2005). "The Culture of revolution: Revolutionary transformation in Iran" (2010). UNLV Theses, Dissertations, Professional Papers, and Capstones. 814, https://dx.doi.org/10.34917/2153789

Kramer, M. S. (1987). Sh'iism resistance and revolution. Westview Press.

Kurt, M. (2018). Safevi dönemi şî̂ ulema ve Velâyet-i Fakih'in ortaya ç1kışını hazırlayan tarihsel süreç üzerine. İran Çalışmaları Dergisi, 2(1), 61-90, https://dergipark.org.tr/tr/download/article-file/554719

Kurun, İ. (2017). İranian political system: "mullocracy". Yönetim ve Ekonomi Araştırmaları Dergisi, 15(1), 114-129, http://dx.doi.org/10.11611/ yead.285351

Lambton, A. (1987). Qajar Persia. University of Texas Press.

Lapıdus, M. I. (2003). İslam toplumları tarihi. (Y. Aktay, Çev.) İletişim Yayınlar1.

Milan, M. (2005). Shi'ism and the state in the Constitution of the Islamic Republic of Iran. İçinde, S. K.Farsoun, \& M. Mashayekhi Iran political culture in the Islamic Republic (s. 92-110). Routledge.

Moaddel, M. (1992). İran'da şii ulema ve devlet. İçinde, S. Üşür (Ed.), Iran Devrimi din anti emperyalizm ve sol (s. 151-198). Belge Yayınları.

Moghadam, M. V. (1994). Islamic populism, class and gender in postrevolutionary Iran. İçinde, J. Foran, A century of revolution: social movements in Iran (s. 189-222) University of Minnesota Press.

Osiewicz, P. (2019, Winter). Ideologizing and fundamentalism in Iranian foreign policy under the Hassan Rouhani presidency. European, Middle Eastern and Arican Affairs, 1(2), 109-121. https:/www.airuniversity.af.edu/Portals/10/JEMEAA/Journals/Volume-01_Issue-2/JEMEAA_01_2_Osiewicz.pdf

Rahimi, B. (2009, January 29). Shi'a politics in Iran after 30 years of revolution: The Iranian Revolution at 30. The Middle East Institute. https:// www.mei.edu/publications/shia-politics-iran-after-30-years-revolution 
Safari, S. (1993). The Legitimation of the clergy's right to rule in the Iranian Constitution of 1979. British Journal of Middle Eastern Studies, 20(1), 68-72, https://doi.org/10.1080/13530199308705571

Sarı, İ. (2015). 1979 devrimi sonrası İran'ın rejim paradigması ve dış politika yönelimleri. Turkish Journal of Middle Eastern Studies, 2(1), 95135, https://dergipark.org.tr/tr/download/article-file/159017

Shambayati, H. (2004). A Tale of two mayors: Courts and politics in Iran and Turkey. International Journal of Middle East Studies, 36(2), 253275, https://doi.org/10.1017/S0020743804362057

Soltani, F., \& Amiri, R. (2010). Foreign policy of Iran after Islamic Revolution. Journal of Politics and Law, 3(2), 199-206, https://doi. org/10.5539/jpl.v3n2p199

Taflıoğlu, S. (2012). İran İslam Cumhuriyeti'nde egemenlik ve meşrûiyet kaynağ1 'Velâyet-i Fakih'. Ankara Üniversitesi SBF Dergisi, 68(3), 95112, https://doi.org/10.1501/SBFder_0000002288

Takeyh, R. (2009). Guardians of the Revolution: Iran and the world in the age of the ayatollahs. Oxford.

Uyar, M. (2000). Velayet-i Fakih' in ortaya çıkışı ve değerlendirilmesi. Dini Araştırmalar, 2(6), 77-98, https://dergipark.org.tr/tr/pub/da/issue/4443/61221

Uyar, M. (2004). Şii Ulemanın otoritesinin temelleri. Kaknüs Yayınları.

Uzun, Ö. S. , \& Ekşi, M. (2017). İran dış politikasında süreklilik ve değişim: Suriye analizi. ANKASAM| Bölgesel Araştırmalar Dergisi, 1(3), 205-228, https://dergipark.org.tr/tr/pub/bader/issue/33344/371186

Varol, F. (2016). The politics of the ulama:Understading the influential role of the ulama in Iran. Milel ve Nihal, 13(2), 129-152, https://doi. org/10.17131/MILEL.284850

Zarif, M. J. (2014, May). What Iran really wants: Iranian foreign policy in the Rouhani Era. Foreign Affairs, 93(3), 49-54, https://www.jstor.org/ stable/24483405

Zubaida, S. (2011). Sects in Islam. İçinde P. B. Clarke (Ed.), The Oxford Handbook of the Sociology of Religion. Oxford, https://doi. org/10.1093/oxfordhb/9780199588961.013.0031 